\title{
Local Candidates, Place-Based Identities, and Electoral Success
}

\author{
Julia Schulte-Cloos ${ }^{1}$ (D) Paul C. Bauer ${ }^{2} \mathbb{D}$
}

Accepted: 17 April 2021

(C) The Author(s) 2021

\begin{abstract}
While a large body of literature empirically documents an electoral advantage for local candidates, the exact mechanisms accounting for this effect remain less clear. We integrate theories on the political geography of candidate-voter relations with socio-psychological accounts of citizens' local attachment, arguing that citizens vote for candidates from their own local communities as an expression of their placebased identity. To test our argument, we exploit a unique feature of the German mixed-member electoral system. We identify the causal effect of candidates' localness by relying on within-electoral-district variation coupled with a geo-matching strategy on the level of municipalities $(\mathrm{N}=11175)$. The results show that voters exhibit a strong bias in favor of local candidates even when they are not competitive. More than only expecting particularistic benefits from representatives, citizens appear to vote for candidates from their own local community to express their placebased social identity.
\end{abstract}

Keywords Local candidates · Electoral behavior · In-group favoritism · Place-based social identity $\cdot$ Political geography

\section{Introduction}

Why do citizens favor candidates from their own local communities? Following Key's (1949) seminal account on 'friends-and-neighbors' voting in the US, researchers have demonstrated that voters across different countries, electoral contexts and

Replication material for this article is stored at the Harvard Dataverse (https://doi.org/10.7910/DVN/ 5ORK7C) and can be accessed online: https://dataverse.harvard.edu/dataset.xhtml?persistentId=doi: 10.7910/DVN/5ORK7C.

Julia Schulte-Cloos

julia.schulte@1mu.de

1 LMU Munich, Oettingenstraße 67, 80538 München, Germany

2 MZES Mannheim, Mannheim, Germany 
political systems prefer candidates with local ties. Previous work has mostly focused on two broad sets of explanations accounting for the electoral advantage of candidates in their hometowns. These are, first, explanations related to the sociotropic correlates of a close geographical proximity between candidates and voters, like a greater contact frequency with candidates, or voters' increased exposure to campaign activities (Arzheimer \& Evans, 2012, 2014; Górecki \& Marsh, 2012). The second set of explanations has highlighted that voters prefer local candidates for strategic-instrumental motivations. According to these explanations, voters expect that a local candidate is better able to represent the interests of their local community or increase spending in favor of it (Childs \&Cowley, 2011; Meredith, 2013; Campbell et al., 2019).

In this article, we contend that voters' preference for local candidates may also be an expression of their place-based social identity. Recent research highlights that territorial identities and sentiments of local belonging can be powerful in shaping political behavior (Cramer, 2016; Enos, 2017; Fitzgerald, 2018). The opportunity to cast a ballot for a fellow citizen from their own local community makes voters' place-based social identities salient. We argue that this increases the in-group bias that voters express in electoral decision-making to the extent that they even favor local candidates who are electorally not competitive. To test our argument, we draw on a rich and novel dataset that combines information on electoral returns at the municipal-level with information on the place of residence of all candidates that competed in the last two parliamentary elections in Germany $(2013,2017)$. We identify the effect of candidates' localness on their electoral success by exploiting within-electoral-district variation in their electoral returns and assess the role of place-based social identities both by means of a novel geo-matching strategy and by means of exploiting a specific feature of the German mixed-member electoral system. While the latter allows us to disentangle voters' strategic-instrumental motivations from the role that their local social identity plays in electoral decision-making, the former tries to hold constant the sociotropic correlates of a close candidate-voter proximity at their maximal potential impact. The results show that candidates fare consistently and significantly better in their home municipalities than in the rest of their electoral districts, resulting in an electoral advantage of around two and a half percentage points. Critically, those single-member district (SMD) candidates who have no prospect of gaining office also benefit from a local electoral advantage. In uncritically favoring candidates from their own local communities, it appears, voters express their place-based social identity.

Our article advances the literature on electoral behavior and localism in several ways. First, we apply the to-date most fine-grained and conservative empirical design to estimate ecological effects of candidates' localness on their electoral performance. By relying on a dataset encompassing $\mathrm{N}=11175$ municipalities nested in 299 single-member district constituencies and using electoral-district-fixed effects, we propose a conservative test for any potential effect of candidates' local residence on their electoral success. The results confirm that candidates fare substantively and significantly better in their hometowns than in the rest of the electoral district. Our within-electoral-district estimation is critical for inference. In the plurality tier of the German mixed-member electoral system, it is not in candidates' interest to succeed 
only in a singular municipality. Instead, candidates aim to attract wide electoral support among all parts of the electoral district, which acts to minimize any potential bias that may result from selective campaigning activities. Second, our article contributes to the literature by comprehensively synthesizing the theoretical arguments proposed in previous accounts and advancing them with respect to the underlying mechanisms that may explain the electoral advantage of local candidates. We study the role of place-based social identities by proposing a novel geo-matching strategy that, as more than just a methodological advancement, allows us to hold constant the sociotropic conditions of a close candidate-voter proximity. It contrasts a candidate's electoral performance to her performance in neighboring municipalities that are not only geographically extremely close to her home municipality (the average distance is less than $8 \mathrm{~km}$ ), but that are also most similar in terms of other characteristics that may promote a greater contact frequency between her and voters. We further isolate the effect of place-based social identities by assessing whether it also operates independently from the strategic-instrumental expectations that voters may have when electing a local candidate as documented by previous scholarship. Our identification strategy exploits the fact that German parties field candidates in all of the SMDs to boost their visibility and their resulting electoral performance in the proportional representation (PR) tier, which is ultimately decisive for the translation of votes to seats. By restricting our analysis to non-competitive SMD candidates, we demonstrate that voters' electoral decision-making is biased towards candidates from their own local communities even when these candidates are without any prospects to gain office.

The article proceeds as follows. In the following section, we review the different theoretical mechanisms that have been proposed in the previous literature to explain candidates' local electoral advantage and derive a set of hypotheses to be tested in this article. We then move to introduce our data and estimation strategy, highlighting how our research design aims to disentangle the different mechanisms accounting for the local electoral advantage. Subsequently, we discuss the results of our study. They confirm that the localness of a candidate affects her vote share even when we hold constant sociotropic correlates of a close candidate-voter proximity by minimising the geographic distance between the units of analysis. Critically, the results further show that this effect is independent from rational-strategic considerations that voters may apply in expectation of redistributional benefits. Voters express a bias for candidates from their own local communities even when those candidates have no prospect of winning office. The final section concludes the study and highlights the need to use individual-level data to further understand the critical role of place-based social identities in explaining friends-and-neighbors voting.

\section{Theory and Evidence: An Advantage for Locals?}

In his seminal work 'Southern Politics in State and Nation', Key highlighted that Democratic candidates in Southern American primaries fare significantly better within their home counties (Key, 1949, p. 37). Ever since, scholars have addressed the so-called 'friends-and-neighbors' effect (Tatalovich, 1975, p. 807; cf. Garand, 
1988, p. 85), providing abundant empirical evidence that it travels beyond the American context of primaries to a variety of electoral contexts and political systems (Tavits, 2010; Arzheimer \& Evans, 2012, 2014; Fiva \& Halse, 2016; Evans, Arzheimer, Campbell, \& Cowley, 2017). While the electoral advantage for local candidates is thus empirically well-documented, the exact mechanisms accounting for this effect remain less clear. Previous scholarship has advanced two broad types of explanations for why voters favor local candidates. First, scholars argue that sociotropic correlates of a close candidate-voter proximity-like more frequent interactions between candidates and voters, or a resulting greater awareness of candidates on behalf of voters-help candidates to succeed in their hometowns. Second, voters may prefer a local candidate in expectation of benefits for their local communities with respect to particularistic spending and descriptive representation. We contend that, in addition to these two broad sets of mechanisms, voters favor local candidates as an expression of their place-based social identity. In the following, we first discuss the previous theoretical accounts and related empirical evidence, before developing our argument in detail.

\section{Geographical Candidate-Voter Proximity and Voters' Expectations of Local Candidates}

Existing accounts that have tried to explain the electoral advantage for local candidates have first argued that voters prefer local candidates as the close geographic proximity allows them to more frequently interact with their potential future political representatives. When candidates and voters are living in close geographical proximity, chances for interactions and contact are higher (Evans et al., 2017, p. 65). Such contacts, in turn, contribute to a greater awareness of candidates on behalf of the voters, reducing their information uncertainty about the candidates or acting to mobilize them. To offer an explanation for the empirical 'friends-and-neighbors' effect, Stokes and Miller (1962) analyzed the variation in voters' awareness of candidates in the 1958 US Congressional election. While they contend that voters are generally not aware of the candidates running for office [p. 544], they find that those voters who live in the same community as candidates are almost 25 percent more aware of the candidates than those who live in a different community. These results are echoed in more recent work. Gimpel, Karnes, McTague, and PearsonMerkowitz (2008) find a non-linear impact of candidate-voter distance on a candidate's electoral success, which they attribute to a decay of voters' familiarity at higher levels of geographical distance. Similarly, studies using individual-level data convincingly demonstrate that individuals indicate greater support for geographically proximate candidates running in British parliamentary (Arzheimer \& Evans, 2012) and British county elections (Arzheimer \& Evans, 2014). Górecki and Marsh (2012) report a decreasing contact-frequency among Irish voters and candidates as the geographic distance between a respondent's estimated residence and candidates' place of residence increases. The relationship is non-linear, with contact decreasing only incrementally for small geographical distances of up to $10 \mathrm{~km}$ but decreasing strongly for high geographical distances (Górecki \& Marsh 2012, p. 568). Contact 
with candidates and exposure to their campaign activities also significantly increases the likelihood that German voters recognize the single-member district candidates running in their district (Gschwend \& Zittel, 2015). Thus, the local electoral advantage of candidates appears to originate in the sociotropic correlates prompted by a close geographical proximity between voters and candidates. These correlates include voters' increased contact and their greater awareness of their potential future representatives.

Second, previous work that tried to explain why local candidates fare better than their non-local counterparts has suggested that voters prefer local candidates because they expect certain benefits from a political representative who comes from their area. These benefits relate both to particularistic spending and to a greater descriptive representation of voters' hometown. Previous research shows that successfully elected candidates engage in "personal vote seeking" by selectively allocating public funding to the respective geographical areas in which they re-run for office. Cain et al. (1987) show that MPs with a higher personal vote incentive (those elected by plurality) have systematically different committee services and are more likely to be on committees with influence over allocation of benefits to geographic constituencies. Thus, the electoral advantage in candidates' hometown may be a product of voters' faith that a "neighbor" in political office will redistribute additional resources to their hometown (Key 1949; Meredith 2013). Next to expectations of particularistic benefits, vote choice for a local candidate may also be motivated by the expectation that a "neighbor" will descriptively represent the issues that matter to a local community. Using a vignette survey experiment with British respondents, Campbell et al. (2019) find evidence that individuals, on average, reward "local behavioralism" by indicating a greater satisfaction with being represented by a fictive local MP who dedicates a lot of time to the work for his local constituency. When asked about the preferred characteristics of candidates or legislators, voters repeatedly contend that being represented by someone from their area is of great concern to them (Johnson and Rosenblatt 2007; Childs and Cowley 2011). Thus, voters appear to favor local candidates in the expectation that a potential future representative from their hometown will provide concrete benefits to their local community. Such potential benefits include a greater allocation of resources or a better descriptive representation in favor of the local community.

Following these two sets of theoretical arguments, we propose a first baseline hypothesis on the effect of a candidate's localness on her electoral performance. As our empirical design draws on the German case, we specify the localness of candidates with respect to their place of residence in a given German municipality.

H1: Candidates perform better in their home municipalities than in the rest of the electoral district.

\section{Vote Choice for Local Candidates as an Expression of Place-Based Identities}

Next to sociotropic correlates of a close candidate-voter proximity and voters' strategic-instrumental expectations towards a potential future legislator, we argue that 
place-based social identities are critical to understand the electoral advantage of local candidates.

Exposed to a given local context, individuals develop an attachment to their local community and the place in which they live, which creates the ground for a shared, place-based social identity among them (Agnew, 1987). Their local environment can instill a deep-rooted sense of belonging in individuals, which even allows them to counterbalance their experiences in an increasingly globalized world (Inglis \& Donnelly, 2011). Enos (2017) draws attention to the social dimension of both historical and contemporary geographies, highlighting that this social dimension of space is critical for the development of a place-based identity among individuals. In carrying such a strong social dimension, place-based identities (Cramer, 2012) are similar to group-based identities. They position the individual as an integral part of the wider group which carries shared characteristics ("our local community", "our municipality"). The salience of a given group membership then acts to impact individuals' attitudes and their decision-making in ways that are consistent with the respective social identity (Sniderman, Hagendoorn, \& Prior, 2004; Van Bavel \& Pereira, 2018).

A common place of residence with a candidate who is running for office presents a relevant signal to voters that the candidate is sharing the same place-based identity and is sensitive to their local every-day life reality (Shugart et al., 2005, p. 438; Jacobs \& Munis, 2019). Such similarity to a candidate may result in a greater level of trust in the candidate (Gimpel et al., 2008) and provide voters with psychological satisfaction when casting a ballot (Lewis-Beck \& Rice, 1983). Parker (1982, p. 244) suggests that voters' choice for local candidates reflects a 'local boy made good syndrome', providing them with a certain satisfaction that one of their own community is running for office. German ballot papers explicitly draw voters' attention to the place of residence of candidates, making their shared place-based identity with a candidate a situationally salient cue in the moment of casting a ballot. ${ }^{1}$ The salience of the shared place of residence, may activate in voters behaviors that are consistent with their place-based social identity and provide them with an expressive satisfaction that is independent of the electoral success of the local candidate in question (Bassi, Morton, \& Williams, 2011).

Consequently, we contend that voters may be motivated to support a local candidate as an expression of their place-based social identity. Voters should exhibit a bias in favor of local candidates from their community even when those candidates do not have any prospects to gain office. In still casting a ballot for a non-competitive, but fellow resident coming from their own local community, voters have a chance to express their placed-based social identity which is made salient on the ballot paper. The electoral advantage of local candidates, thus, may also operate independently from an increased frequency of contact or any strategic-instrumental considerations on behalf of the voters. Consequently, we argue:

\footnotetext{
1 See Figure A4 in the Appendix for a sample ballot paper of one electoral district in Germany. The information on candidates' place of residence is printed below the names of the candidates.
} 
H2: Candidates perform better in their home municipalities than in otherwise similar, neighboring municipalities, even if they have no prospect of winning a majority in the single-member district.

\section{Data, Measures, and Identification Strategy}

The German national electoral system combines a plurality formula within 299 different single-member districts with a system of proportional representation that relies on closed party lists across the 16 different states. Each voter casts two different votes - Vote 1 and Vote 2 - that do not need to be congruent. Voters use Vote 1 ("Erststimme") to vote for a single-member district candidate in their electoral district. In each electoral district, the candidate with the most votes from this electoral tier enters the German parliament. Vote 2 ("Zweitstimme") is given to a party list and determines the proportional share of seats a party will obtain in the German parliament. Only this proportional vote share of the second tier of the German electoral system is decisive in translating the votes into seats. Yet, before the electoral mandates are distributed to the different candidates on the parties' lists, those candidates of a party who successfully won a single-member districts in any of the 299 electoral districts are preferentially taken into account. Thus, the German electoral system classifies as a "compensatory proportional-mixed system" (Shugart \& Wattenberg, 2001).

Evidently, not all parties have equal prospects to win any of the single-member districts. As the candidates need to achieve a plurality in their electoral district to gain office, mainstream parties enjoy better prospects to win the single-member districts than smaller parties. Notwithstanding these differences in the chances to gain office, all relevant parties tend to field candidates in the single-member districts. These candidates are deemed decisive to lend the party a more personal and tangible character during the election campaign (Cox \& Schoppa, 2002, p. 1031). Our study exploits this feature of the German electoral system, which we explain in greater detail below.

In our analysis, we exploit the variance in electoral support for each candidate across all municipalities that belong to the same electoral district. The units of analysis are municipalities, which are nested in electoral districts in which single-member district candidates are running for office. ${ }^{2}$ Hence, focusing on this level allows us to exploit within-electoral-district variance of each candidate's localness and electoral result across municipalities. We compare a candidate's vote share in a municipality in which she lives to her vote share in a municipality in which she does not live but which is part of the same electoral district, i.e., we compare units that are socio-structurally and socio-demographically otherwise highly similar.

We create a novel dataset that encompasses municipal-level electoral data on the vote share from the first tier during the two most recent German federal elections

\footnotetext{
${ }^{2}$ Note that a few municipalities $(\mathrm{N}=68)$ consist of several electoral districts, which need to be excluded from our analyses as there is no municipal-level variance within an electoral district.
} 
a Bavaria:

Location within Germany

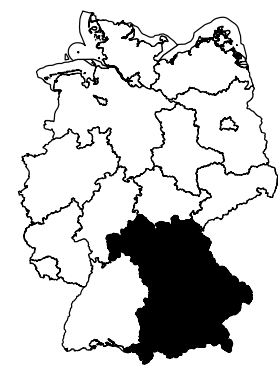

b Electoral district 213: Location within Bavaria

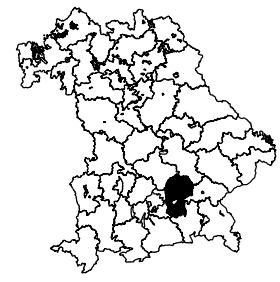

C Electoral district 213: Municipalities with (blue) and without (gray) local candidates (Ebersberger forest shown in stripes)

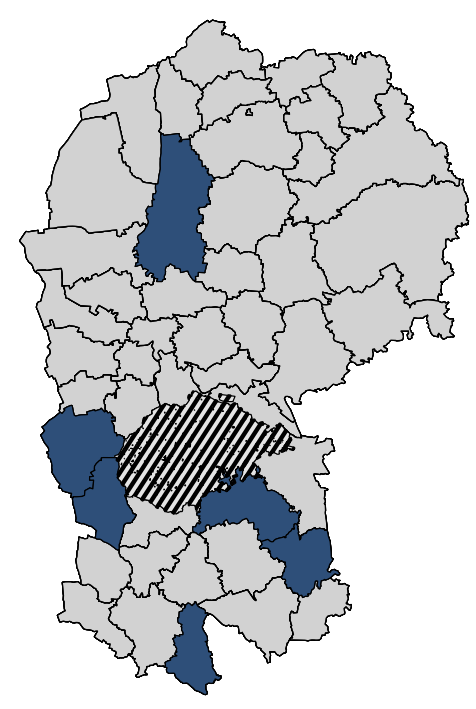

Fig. 1 Illustration of the identification strategy: candidates' residences within certain municipalities in each of the 299 electoral districts. The illustration shows electoral district 213 Ebersberg - Erding

that took place in 2013 and 2017 linked to data on all candidates from the six major German parties and to geo-spatial information for all municipalities. ${ }^{3}$ Research on electoral candidates is notoriously difficult as data on all candidates who are not elected is hardly available (Tavits 2010, p. 219). We obtain the data on all German candidates that ran for office from the Federal Returning Officer. These data include the place of residence of candidates, which is also printed on the ballot paper. We use the information on candidates' places of residence to measure their status as local vs. non-local candidates. In the resulting municipal-level dataset, we observe the electoral outcome that each German party achieved in the first tier, leaving us with a dataset covering $\operatorname{party}(=$ candidate $) \times$ municipality observations.

As electoral districts consist of several municipalities (mean number of municipalities: 46.74), to win the electoral mandate, each single-member district candidate needs to obtain wide electoral support across all of these municipalities. Each candidate, however, only resides in one of these municipalities. In 2013, there are 809 municipalities in which voters could cast a ballot for a local candidate, whereas voters in 10234 municipalities did not have the chance to vote for someone from their own municipality. In 2017 , the former is the case for voters of 844 municipalities,

\footnotetext{
3 The Appendix (A.1) provides more details on the process of linking the various data sources and creating an integrated dataset.
} 
Table 1 Vote shares of candidates in their home municipalities (local) and their average vote shares in the remaining municipalities (nonlocal) of an electoral district. For illustrative purposes, the table reports the vote shares in electoral district 213 Ebersberg Erding in the federal election of 2017

\begin{tabular}{lll}
\hline Party & Local vote share & $\begin{array}{l}\text { Average } \\
\text { non-local vote } \\
\text { share }\end{array}$ \\
\hline AfD & 7.08 & 10.95 \\
CDU/CSU & 68.69 & 50.22 \\
Die Linke & 5.91 & 3.56 \\
FDP & 13.67 & 6.62 \\
Greens & 10.48 & 9.43 \\
SPD & 20.15 & 12.79 \\
\hline
\end{tabular}

whereas the majority of citizens still could not vote for a locally resident fellow citizen $(\mathrm{N}=10165){ }^{4}$

Figure 1 illustrates our comparative strategy. Plot a) displays Germany and its 16 federal states, highlighting the state of Bavaria in black. Plot b) zooms into Bavaria and displays the electoral districts within the state of Bavaria (electoral district 213 Ebersberg - Erding coloured in black). Single-member district candidates are running on the level of these electoral districts. For any level below the level of electoral districts, the ballot papers and the set of candidates from among which voters can choose is constant. This allows us to identify the localness effect by further zooming in on the level of municipalities. Plot c) depicts the municipalities that are located within the electoral district 213 Ebersberg - Erding (one of 299 districts) that we describe in some detail for illustrative purposes. Electoral district 213 Ebersberg - Erding, in turn, comprises 47 different municipalities.

The municipalities coloured in blue in Figure 1 (Plot c) represent the home municipalities of the six different candidates. ${ }^{5}$ The candidate from the conservative party (CDU/CSU) won the electoral district 213 - Ebersberg Erding with a clear margin (48.2 percent of the vote), while the other five candidates each obtained less than 15 percent of the vote. The interest of our study is the variance in electoral support for the different parties within each electoral district as a function of the localness of their candidates. Table 1 illustrates this variance in electoral support for the candidates in the electoral district 213 Ebersberg - Erding.

As can be seen from Table 1, with the exception of the candidate of the German populist radical right party AfD, the electoral support for all candidates is substantively higher in the municipality in which they live than in the remaining municipalities of the electoral district. It appears that being a local resident substantively boosts the electoral prospects of single-member district candidates within their

\footnotetext{
${ }^{4}$ Ideally, we could also observe changes in the localness of the same candidates across time, i.e., for candidates who ran for office in both years but changed their place of residence within their electoral district. Yet place of residence is a remarkably stable characteristic among political candidates in Germany. There are 350 candidates among the 2272 candidates in our data that ran for office in both of the elections. Among them, however, only 17 candidates changed their residence.

5 There are also some un-inhabited areas in this electoral district, a large forest called "Ebersberger Forest", which is shown in stripes on the map.
} 
municipalities. Our illustrative example also highlights that the "localness effect" even works to augment the electoral support for those candidates who are far from having any realistic prospects of winning a simple majority in their electoral district, which we shall exploit later when considering the potential mechanisms that may account for the electoral advantage of local candidates. Before assessing whether we find systematic evidence for similar electoral benefits for all local candidates during the last two German federal elections, we discuss the central assumptions of our identification strategy that are critical to isolating the effect of candidates' localness on their electoral performance and address potential confounders.

As we measure the outcome with reference to a candidate's electoral performance in other municipalities within the same electoral district, and as it is the objective of each candidate to maximize her vote share across the entire electoral district, we have good reason to assume that candidates do not choose to live in any specific municipality in anticipation of specific electoral advantages in that singular municipality. Thus, a potential endogeneity of our findings resulting from selective moving of candidates within an electoral district after their nomination does not appear to challenge our research design. Yet, certain municipalities within an electoral district may represent party-specific electoral strongholds. This characteristic should at the same time increase the probability that a qualified candidate from that municipality runs for office on the platform of the given party, i.e., that she is nominated in the first place. As the local party chapters in Germany are responsible for nominating the SMD candidates and strong local party chapters may have a larger pool of candidates to draw from or may enjoy a greater influence in the district-level nomination procedure, we add a covariate to our model that measures the strength of a party's electoral base in a municipality. We measure this strength of an electoral base by the average municipal-level vote share that a candidate's party obtained in the PR tier of the German electoral system across the two federal elections preceding the respective election under study. ${ }^{6}$ Figure A1 in the Appendix highlights that most electoral districts are rather homogeneous clusters of municipalities with respect to the strength of each party's electoral base. Only a few municipalities deviate substantively from the prevalent district-level average strength of electoral support, while the median deviation is as small as 0.14 percentage points of a party's average vote share.

All candidate-specific characteristics (like a candidate's gender, her status as MP, her occupation, or her physical appearance) are held constant across the local and non-local municipalities as voters in all municipalities within each electoral district are presented with the same choice set on their ballot. To some extent, the "meaning" of the ballot choice set may, however, vary across municipalities within the same electoral district depending on their average socio-economic and socio-demographic

\footnotetext{
${ }^{6}$ We are relying on the vote share of the $P R$ tier to measure the average partisan preferences within a given municipality in a more proportional manner that is less biased towards majoritarian tendencies as the plurality tier. We are further using the two preceding elections to have a clear "pre-treatment" measure of a party's stronghold that is not affected by the central independent variable of interest, i.e., the localness of candidates. See Fiva and Halse (2016) for similar arguments.
} 
characteristics. Therefore, we control for a number of municipal-level covariates that could, on average, impact voters' evaluation of the candidates' choice set. We control for the number of inhabitants, the geographical size of a municipality (LewisBeck \& Rice, 1983), its degree of urbanization (Blais et al., 2003; Meredith, 2013), and whether another local candidate is running for office (Put, von Schoultz, \& Isotalo, 2020).

\section{Results}

We begin by assessing our baseline hypothesis $H 1$, which holds that local candidates fare better in their home municipalities than in the remaining parts of the electoral district. In attempting to investigate the underlying mechanisms and to scrutinize the role of place-based social identities, we then proceed in two steps. First, we assess whether the effect persists when we hold constant sociotropic conditions of a close geographical proximity between candidates and voters. As previous accounts argue that interactions between candidates and voters are facilitated when voters live close to candidates, in this first step, we focus only on the home municipalities of candidates and the directly adjacent municipalities that are socio-demographically most similar to the former. To identify this subset of municipalities, we rely on a geo-matching strategy, which we discuss in detail below. In a second step, we study whether the localness effect is independent of voters' strategic-instrumental motivations. To do so, we assess whether even non-competitive candidates benefit from the localness effect $(H 2)$. We compare their performance in their home municipalities both against their performance in the entire rest of the electoral district and their performance in the geo-matched subset of neighboring municipalities.

\section{The Electoral Advantage for Local Candidates}

Columns 1 and 2 of Table 2 present the results of our baseline hypothesis $H 1$ by contrasting a candidate's vote share in her home municipality with her vote share in all other municipalities within the same electoral district. All models report standard errors clustered at the electoral district-level. We find that local candidates, on average, perform 2.67 percentage points better in their home municipalities than in the remaining municipalities of the same electoral district (see column 1 of Table 2). The effect size is very similar for local candidates in the federal election of 2017 (see column 2 of Table 2). In all those municipalities where voters had the chance to cast a ballot for a local fellow citizen, the respective candidate fared 2.99 percentage points better than in the rest of the electoral district. This confirms the empirical findings of the rich literature on friends-and-neighbors voting and gives support to our baseline hypothesis $H 1$. The results are also robust to estimate a fractional response model $^{7}$ (see columns 5 and 6 of Table A7 in the Appendix), which we

\footnotetext{
7 The fractional response model (FRM) as proposed by Papke and Wooldridge (1996) presents an extension to the generalized linear model for continuous variables measured as proportions, i.e., they are bounded between zero and one, and relies on quasi-maximum likelihood estimation. We estimate a logit
} 
Table 2 Effect of candidates' localness on their vote share

\begin{tabular}{|c|c|c|c|c|}
\hline & \multicolumn{2}{|c|}{ All municipalities } & \multicolumn{2}{|c|}{ Geo-matched municipalities } \\
\hline & 2013 & 2017 & 2013 & 2017 \\
\hline Local $(0,1)$ & $\begin{array}{l}2.665^{* * * *} \\
(0.179)\end{array}$ & $\begin{array}{l}2.993 * * * \\
(0.187)\end{array}$ & $\begin{array}{l}2.343 * * * \\
(0.221)\end{array}$ & $\begin{array}{l}2.784 * * * \\
(0.240)\end{array}$ \\
\hline Multiple candidates $(0,1)$ & $\begin{array}{l}-0.926^{* * *} \\
(0.186)\end{array}$ & $\begin{array}{l}-0.997 * * * \\
(0.175)\end{array}$ & $\begin{array}{l}-0.992 * * * \\
(0.332)\end{array}$ & $\begin{array}{l}-1.192 * * * \\
(0.324)\end{array}$ \\
\hline Electoral base & $\begin{array}{l}0.797 * * * \\
(0.004)\end{array}$ & $\begin{array}{l}0.766^{* * *} \\
(0.004)\end{array}$ & $\begin{array}{l}0.841 * * * \\
(0.016)\end{array}$ & $\begin{array}{l}0.856^{* * *} \\
(0.017)\end{array}$ \\
\hline Area $\left(\mathrm{km}^{2}\right)$ & $\begin{array}{l}0.000 \\
(0.001)\end{array}$ & $\begin{array}{l}-0.001 \\
(0.001)\end{array}$ & $\begin{array}{l}-0.011^{* * *} \\
(0.003)\end{array}$ & $\begin{array}{l}-0.010^{* * * *} \\
(0.003)\end{array}$ \\
\hline Inhabitants (1000) & $\begin{array}{l}-0.004 * \\
(0.002)\end{array}$ & $\begin{array}{l}-0.005^{* *} \\
(0.002)\end{array}$ & $\begin{array}{l}0.007 \\
(0.005)\end{array}$ & $\begin{array}{l}0.000 \\
(0.004)\end{array}$ \\
\hline Urbanization & $\begin{array}{l}0.015^{* * *} \\
(0.003)\end{array}$ & $\begin{array}{l}0.008^{* * * *} \\
(0.003)\end{array}$ & $\begin{array}{l}-0.048^{* * * *} \\
(0.012)\end{array}$ & $\begin{array}{l}-0.040^{* * * *} \\
(0.012)\end{array}$ \\
\hline Electoral-District-Fixed Effects & $\checkmark$ & $\checkmark$ & $\checkmark$ & $\checkmark$ \\
\hline Party-Fixed Effects & $\checkmark$ & $\checkmark$ & $\checkmark$ & $\checkmark$ \\
\hline Intercept & $\begin{array}{l}-29.209 * * * \\
(0.228)\end{array}$ & $\begin{array}{l}-3.940 * * * \\
(0.190)\end{array}$ & $\begin{array}{l}-27.484 * * * \\
(1.251)\end{array}$ & $\begin{array}{l}-4.308^{* * * *} \\
(1.664)\end{array}$ \\
\hline $\mathrm{R}^{2}$ & 0.96 & 0.91 & 0.96 & 0.91 \\
\hline Num.Obs. & 51245 & 54224 & 3144 & 3381 \\
\hline
\end{tabular}

$* \mathrm{p}<0.1, * * \mathrm{p}<0.05, * * * \mathrm{p}<0.01$

All models report robust standard errors clustered at the electoral district-level

estimate to address the fact that a small fraction of the predicted values of our OLS regressions fall below zero. Figure A3 in the Appendix visualises the distribution of predicted values for all estimated models, highlighting that our model correctly predicts a candidate's vote share to be greater than zero in most cases ( 97.47 percent of all observations).

Taken together, these findings demonstrate that candidates perform significantly better in their home municipalities than in the rest of the electoral district in which they run for office. In the following, we approach the mechanisms accounting for this localness effect, trying to assess whether voters' place-based social identities contribute to the success of local candidates.

\section{Place-Based Identities and Vote Choice for Local Candidates}

We first focus on the subset of municipalities that are geographically closest to a candidate's home municipality while being most similar in socio-demographic

Footnote 7 (continued)

formulation of the FRM model using electoral district and party-fixed effects and report robust standard errors clustered at the electoral district-level. 
Party/Candidate: AfD

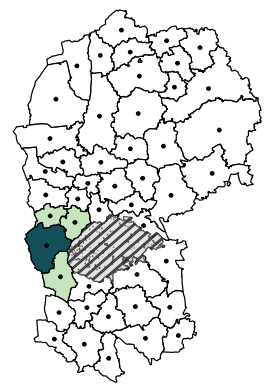

Party/Candidate: FDP

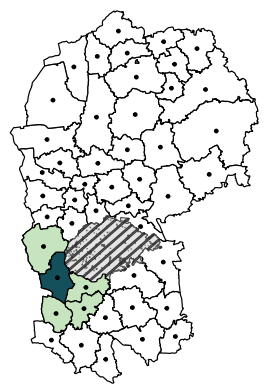

Party/Candidate: $\mathrm{CDU} / \mathrm{CSU}$

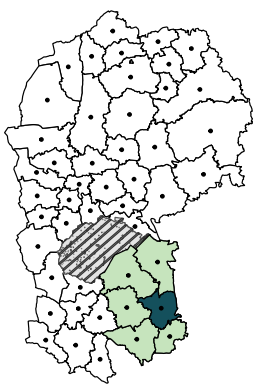

Party/Candidate: Greens

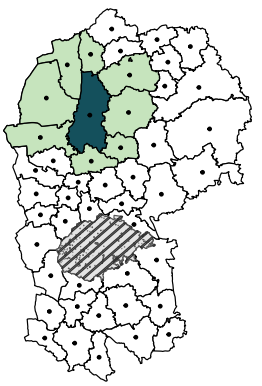

Party/Candidate: SPD

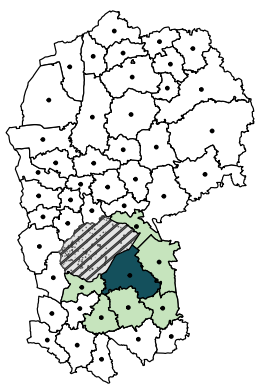

Party/Candidate: Die Linke

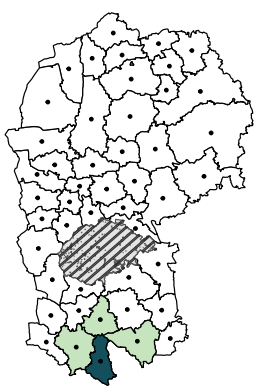

Local Candidate

0

Fig. 2 Illustration of the geographic matching strategy: home municipality of each party's candidate and all adjacent municipalities that serve as potential control cases. The illustration shows electoral district 213 Ebersberg - Erding (Ebersberger forest shaded in gray stripes)

terms. In line with arguments about a decay of candidate-voter interactions only at higher levels of geographical distance (Gimpel et al., 2008; Górecki \& Marsh, 2012), among this geo-matched subset of municipalities, we should be able to hold constant sociotropic correlates of a close candidate-voter proximity. This allows us to assess whether the localness effect persists independently of increased contact with candidates or greater levels of personal familiarity with the SMD candidates. ${ }^{8}$ We identify this subset of municipalities by means of a geo-matching strategy.

Our geo-matching strategy first identifies all municipalities that are directly adjacent to the treated municipalities. This procedure is visualized in Fig. 2, highlighting

\footnotetext{
${ }^{8}$ Given the administrative division of Germany into 299 electoral districts, by definition, the municipalities that are part of the same electoral district are already spatially very close to each other; the average distance between the polygon centroid of a candidate's home municipality and the polygon centroids of the remaining municipalities of an electoral district is $24.69 \mathrm{~km}$. Similar to Fiva et al. (2021), we also consider only candidates that reside in the respective electoral district in which they are running for office. Thus, our baseline estimates of a localness effect are already more conservative than those of previous studies that also exploit variation in candidates' place of residence beyond their constituency in which they are running for office (e.g., Arzheimer \& Evans, 2012; Campbell et al. 2019)
} 
the different home and neighboring municipalities of the six respective candidates running for office in the aforementioned electoral district 213 Ebersberg - Erding. The black points denote the polygon centroids of the municipalities in question. As there is no information on the exact coordinates of candidates' places of residence, in the following we refer to the average distance between candidates and voters by relying on these polygon centroids of municipalities. After having identified the adjacent municipalities, the geo-matching strategy then applies genetic optimal matching to identify the two municipalities that are as similar as possible to the home municipalities of the respective SMD candidates. ${ }^{9}$ We maximize covariate balance on all continuous variables, namely a municipality's prior partisan preferences, its degree of urbanization, geographical size, or the number of its inhabitants. Table A4 and Table A5 in the Appendix provide summary statistics on the balance on covariates in the full sample and the geo-matched subset of municipalities, highlighting that our geo-matching strategy succeeds in minimising the differences between candidates' home municipalities and the neighboring municipalities that serve as comparison group.

Columns 3 and 4 of Table 2 show that the results persist under this geo-matching design. Being a local fellow citizen helps SMD candidates, on average, to gain 2.34 and 2.78 percentage points, respectively, in 2013 and 2017 (see column 3 and column 4 of Table 2). This effect is comparable to the overall effect reported in columns 1 and 2, and its magnitude is remarkable in view of the proximity and similarity of the municipalities in this subset of the data. The average distance between the centroid of a candidate's home municipality and the centroids of the adjacent most similar municipalities identified by the genetic matching algorithm is only $7.99 \mathrm{~km}$. This close geographical proximity should act to level all differences among the units of analysis that relate to sociotropic correlates of a close candidate-voter proximity. Even when contrasting local communities in which voters have the same chances to personally interact with their potential future political representatives, we find that SMD candidates, on average, are performing better within the very administrative boundaries of their home municipalities. ${ }^{10}$ It appears that the differences in electoral returns cannot be explained by differences in sociotropic correlates of spatial candidate-voter proximity alone.

In trying to further scrutinize the role of place-based social identities, we next move to assess whether voters exhibit a bias towards candidates from their local community independently from any strategic-instrumental reasons that may motivate them to vote for a SMD from their home municipality (H2). To do so, we focus only on those political candidates that have no prospect of winning the SMD in

\footnotetext{
9 We use a genetic optimal matching (GenMatch) algorithm (Diamond and Sekhon 2013), relying on 1:2 matching with replacement. GenMatch uses an evolutionary search algorithm developed by Mebane and Sekhon (1998) and automates this process to iteratively check, improve, and maximize the balance of observed covariates across matched treated and control units (Diamond \& Sekhon, 2013, p. 932f). The replacement avoids any bias that may result from finding matches in the same order that the data are sorted (for a detailed discussion of the matching algorithm, see the documentation of the R software package Matching (Sekhon, 2008).

${ }^{10}$ Table A8 in the Appendix further shows that the effect holds both for the subset of municipalities with, on average, smaller and larger than median-levels of distance between the polygon centroids of home and neighboring municipalities.
} 
Table 3 Effect of candidates' localness on their vote share among non-competitive candidates

\begin{tabular}{|c|c|c|c|c|}
\hline & \multicolumn{2}{|c|}{ All municipalities } & \multicolumn{2}{|c|}{ Geo-matched municipalities } \\
\hline & 2013 & 2017 & 2013 & 2017 \\
\hline Local $(0,1)$ & $\begin{array}{l}2.553^{* * * *} \\
(0.199)\end{array}$ & $\begin{array}{l}2.431 * * * \\
(0.218)\end{array}$ & $\begin{array}{l}2.368 * * * \\
(0.219)\end{array}$ & $\begin{array}{l}2.379 * * * \\
(0.261)\end{array}$ \\
\hline Multiple candidates $(0,1)$ & $\begin{array}{l}-0.754 * * * \\
(0.163)\end{array}$ & $\begin{array}{l}-0.854 * * * \\
(0.169)\end{array}$ & $\begin{array}{l}-0.811^{* *} \\
(0.347)\end{array}$ & $\begin{array}{l}-1.277 * * * \\
(0.323)\end{array}$ \\
\hline Electoral base & $\begin{array}{l}0.211^{* * * *} \\
(0.006)\end{array}$ & $\begin{array}{l}0.574 * * * \\
(0.010)\end{array}$ & $\begin{array}{l}0.299 * * * \\
(0.037)\end{array}$ & $\begin{array}{l}0.808 * * * \\
(0.048)\end{array}$ \\
\hline Area $\left(\mathrm{km}^{2}\right)$ & $\begin{array}{l}-0.001 * \\
(0.000)\end{array}$ & $\begin{array}{l}0.000 \\
(0.001)\end{array}$ & $\begin{array}{l}-0.007 * * \\
(0.003)\end{array}$ & $\begin{array}{l}-0.004 \\
(0.004)\end{array}$ \\
\hline Inhabitants (1000) & $\begin{array}{l}0.004 * * \\
(0.002)\end{array}$ & $\begin{array}{l}0.002 \\
(0.002)\end{array}$ & $\begin{array}{l}0.005^{*} \\
(0.003)\end{array}$ & $\begin{array}{l}-0.001 \\
(0.004)\end{array}$ \\
\hline Urbanization & $\begin{array}{l}0.015^{* * *} \\
(0.002)\end{array}$ & $\begin{array}{l}0.024 * * * \\
(0.003)\end{array}$ & $\begin{array}{l}-0.028 * * \\
(0.011)\end{array}$ & $\begin{array}{l}-0.019 \\
(0.014)\end{array}$ \\
\hline Electoral-district-fixed effects & $\checkmark$ & $\checkmark$ & $\checkmark$ & $\checkmark$ \\
\hline Party-fixed effects & $\checkmark$ & $\checkmark$ & $\checkmark$ & $\checkmark$ \\
\hline Intercept & $\begin{array}{l}-5.544 * * * \\
(0.255)\end{array}$ & $\begin{array}{l}-1.408^{* * *} \\
(0.262)\end{array}$ & $\begin{array}{l}-7.723^{* * *} \\
(1.550)\end{array}$ & $\begin{array}{l}-5.945^{* * * *} \\
(1.857)\end{array}$ \\
\hline $\mathrm{R}^{2}$ & 0.68 & 0.57 & 0.72 & 0.65 \\
\hline Num.Obs. & 31186 & 34877 & 1919 & 2198 \\
\hline
\end{tabular}

$* \mathrm{p}<0.1, * * \mathrm{p}<0.05, * * * \mathrm{p}<0.01$

All models report robust standard errors clustered at the electoral district-level

which they are running for office. As discussed above, all major parties tend to field candidates in all SMD electoral districts $(\mathrm{N}=299)$ of the Germany mixed-member electoral system, while only a few have prospects to gain office. We exploit this setting to isolate the effect of voters' place-based social identities on the local advantage of candidates.

We measure the competitiveness of candidates by relying on the history of electoral performance of their party in the plurality tier over the past two elections. While it is difficult to measure electoral competitiveness in multi-member districts, this exercise is more straightforward in the context of single-member districts (Cox et al. 2020). We consider a candidate competitive if the difference between her vote share and that of the winning candidate was less than half as big as the size of the vote share of the leading candidate during any of the two previous parliamentary elections. $^{11}$

Table 3 provides the results for Hypothesis $H 2$. While columns 1 and 2 of Table 3 contrast municipalities with a non-competitive, local candidate to all

\footnotetext{
11 Our measure of electoral competitiveness, thus, allows for different levels of competitiveness across electoral districts. The Appendix reports some empirical examples that motivate this relative measure of competitiveness.
} 
other municipalities within the same electoral district, columns 3 and 4 report the same estimates while focusing on the subset of optimally balanced municipalities identified through our geo-matching strategy. Voters may favor local candidates not only for strategic-instrumental reasons, hoping for larger spending or better descriptive representation to their advantage, but also because their vote choice offers them a chance to express their place-based social identity. If this were the case, we should still find an effect of candidates' localness when considering only those candidates who have no prospects to gain office. Table 3 gives support to this notion. When contrasting the success of a candidate within her home municipality to her success across all other municipalities of her electoral district (columns 1 and 2), we find an average local electoral advantage of 2.55 percentage points in 2013 and 2.43 percentage points in 2017 . These results are also robust to use an absolute measure of candidate competitiveness that classifies all such candidates as non-competitive whose party did not achieve more than 20 percent of the popular vote in the respective electoral district in question over the past two parliamentary elections (see columns 3 and 4 of Table A7 in the Appendix).

Critically, the effect persists when we focus on the subset of municipalities for which we can hold constant the effect of potential sociotropic drivers of friendsand-neighbors voting. Like beforehand, we rely on geo-matching and restrict the analysis to comparing a non-competitive candidate's vote share in her home municipality to the vote share she achieved in the two most similar, closest neighboring municipalities (see columns 3 and 4 of Table 3). The distance between the polygon centroids of the municipalities included in this geo-matched subset of the data, on average, is again only $8.02 \mathrm{~km}$, which allows us to assume that opportunities for personal contact between voters and candidates should be kept sufficiently constant between the units of analysis and should not systematically relate to the strict administrative boundaries of the municipalities. We still find that voters express a bias towards SMD candidates from their own communities. On average, even non-competitive candidates perform 2.37 percentage points (2013), and 2.38 percentage points (2017) better in their own local communities. While still voting for a candidate from their own local community, without any hope that this candidate might also be able to win the SMD, some voters appear to express their place-based social identity on the ballot paper.

Taken together, our findings give support to $H 2$ in demonstrating that even among non-competitive candidates, localness has a positive effect on a candidate's vote share. It appears that in all those municipalities in which voters could spot the name of their own municipality printed on the ballot paper, represented by the nomination of a fellow citizen without any prospects to win a mandate, they felt encouraged to express their local social identity by still voting for such a hopeless candidate and thereby even "wasting" their vote. This finding is remarkable in highlighting that strategic-instrumental motivations or sociotropic drivers alone cannot account for the localism effect that has been extensively documented in the previous literature. Instead, voters seem to also be guided by their placebased social identity when expressing an in-group bias in favor of a candidate from their local community. 


\section{Conclusion}

Following seminal work by Key (1949), scholars have convincingly shown that local candidates enjoy an advantage within the geographical regions they come from. While extensive empirical evidence across countries and a wide array of different electoral systems confirms this pattern, the mechanisms accounting for the "localness effect" remain less clear.

In this article, we advance the argument that voters' preference for local candidates may also be an expression of their place-based social identity. Social identities help individuals to identify with a given group and incorporate a group membership into their self-concept (Tajfel, Billig, Bundy, \& Flament, 1971). Situational cues can make individuals' social identities salient, activating behaviors that are consistent with the respective identity in question and increasing their inclination to express in-group biases (Sniderman et al., 2004; Van Bavel \& Pereira, 2018). We contend that the local roots of political candidates act as social identity cues to voters. These cues are highlighted on the ballot paper, which should make voters' place-based social identities salient and guide their electoral behavior. We expect that voters engage in a form of expressive voting in line with their local group membership to the extent that they favor even such local candidates who are not electorally competitive.

To test our argument, we present an original and rich dataset that integrates data on electoral returns at the municipal-level with data on the place of residence of all candidates who competed in the last two parliamentary elections in Germany $(2013,2017)$. We identify the effect of candidates' localness on their electoral success by exploiting within-electoral-district variation in their electoral returns. The German setting allows us to exploit a unique feature of the mixedmember electoral system: while all major parties that are successful in the PR tier of the German electoral system tend to field candidates in the single-member districts, only a fraction of them has prospects to gain office in this tier that operates according to a plurality principle. Our results confirm that candidates, on average, fare consistently and significantly better in their home municipalities than in the rest of the electoral district. Notably, however, those single-member district candidates who have no prospect of gaining office also benefit from a local electoral advantage, even in a most conservative design that holds constant sociotropic drivers of the localness effect. In favoring candidates from their own local community, voters seem to be guided by their place-based social identity. Highlighted on the ballot paper, a shared place of residence with a candidate appears to act as a situational cue that makes voters' place-based social identity salient. This finding appears critical not only in advancing our understanding of localism effects in voting; it also sheds light on the implications of social identities for electoral behavior, more generally.

Future research should try to corroborate our findings by using individual-level data. Other studies concerned with understanding voters' preferences for local candidates have convincingly linked voters' precise place of residence to those of political candidates running for office (Arzheimer \& Evans, 2014). To apply such 
a research design to the German case, we would need a large number of individual-level observations from the same electoral district to maintain our conservative within-electoral-district estimation. Future research should also try to understand whether some individuals rely more on their place-based social identities in electoral decision-making than others. It should also investigate whether factors related to the information environment (Bassi et al., 2011) or the salience of geographical inequality (Cramer, 2012) can explain such potential variance. Evidently, Germany is not the only country that applies a mixed-member electoral system to elect candidates, and place-based social identities might also matter for voting behavior in plurality or flexible-list preference voting systems. Thus, future research should validate the results presented in this study with evidence from other countries to help broaden our understanding of the role of place-based social identities in voting behavior across different political contexts.

In highlighting the effect of place-based social identities on voting, our study contributes to a nascent body of literature on the social geography of contemporary democracies, reflecting a renewed interest in the social ramifications of political space. The origins of the well-documented "friends-and-neighbor" effect appear to lie also in a form of expressive voting, where voters aim to affirm local identities, rather than following strategic motivations or reacting to sociotropic factors.

Supplementary Information The online version of this article (https://doi.org/10.1007/s11109-02109712-y) contains supplementary material, which is available to authorized users.

Acknowledgements We would like to thank four anonymous reviewers and the editors of this journal for their excellent and very constructive feedback. This project has received funding from the European Union's Framework Programme for Research and Innovation Horizon 2020 under the Marie SkłodowskaCurie Grant Agreement No. 754388 (LMUResearchFellows) and from LMUexcellent, funded by the Federal Ministry of Education and Research (BMBF) and the Free State of Bavaria under the Excellence Strategy of the German Federal Government and the Länder.

Funding Open Access funding enabled and organized by Projekt DEAL.

Open Access This article is licensed under a Creative Commons Attribution 4.0 International License, which permits use, sharing, adaptation, distribution and reproduction in any medium or format, as long as you give appropriate credit to the original author(s) and the source, provide a link to the Creative Commons licence, and indicate if changes were made. The images or other third party material in this article are included in the article's Creative Commons licence, unless indicated otherwise in a credit line to the material. If material is not included in the article's Creative Commons licence and your intended use is not permitted by statutory regulation or exceeds the permitted use, you will need to obtain permission directly from the copyright holder. To view a copy of this licence, visit http://creativecommons.org/licen ses/by/4.0/.

\section{References}

Agnew, J. A. (1987). Place and politics: The geographical mediation of state and society. Abingdon, Oxon: Routledge.

Arzheimer, K., \& Evans, J. (2012). Geolocation and voting: Candidate-voter distance effects on party choice in the 2010 UK general election in England. Elsevier Political Geography, 31, 301-310.

Arzheimer, K., \& Evans, J. (2014). Candidate geolocation and voter choice in the 2013 English county council elections. England Research \& Politics, 1, 1-9. 
Bassi, A., Morton, R. B., \& Williams, K. C. (2011). The effects of identities, incentives, and information on voting. The Journal of Politics, 73, 558-571.

Blais, A., Gidengil, E., Dobrzynska, A., Nevitte, N., \& Nadeau, R. (2003). Does the local candidate matter? Candidate effects in the Canadian election of 2000. Canadian Journal of Political Science, 36(3), 657-657.

Cain, B., Ferejohn, J., \& Fiorina, M. (1987). The Personal Vote: Constituency Service and Electoral Independence. Cambridge, Massachusetts: Harvard University Press.

Campbell, R., Cowley, P., Vivyan, N., \& Wagner, M. (2019). Why friends and neighbors? Explaining the electoral appeal of local roots. The Journal of Politics, 81, 937-951.

Childs, S., \& Cowley, P. (2011). The politics of local presence: Is there a case for descriptive representation? England Political Studies, 59, 1-19.

Cox, G. W., Fiva, J. H., \& Smith, D. M. (2020). Measuring the competitiveness of elections. Political Analysis, 28, 168-185.

Cox, K. E., \& Schoppa, L. J. (2002). Interaction effects in mixed-member electoral systems: Theory and evidence from Germany, Japan, and Italy. Comparative Political Studies, 35, 1027-1053.

Cramer, K. J. (2012). Putting inequality in its place: Rural consciousness and the power of perspective. American Political Science Review, 106(3), 517-532.

Cramer, K. J. (2016). The politics of resentment: Rural consciousness in Wisconsin and the rise of Scott Walker. Chicago, London: University of Chicago Press.

Diamond, A., \& Sekhon, J. S. (2013). Genetic matching for estimating causal effects: A general multivariate matching method for achieving balance in observational studies. Review in Economics Statistics, 95, 932-945.

Enos, R. D. (2017). The space between us: Social geography and politics. Cambridge: Cambridge University Press.

Evans, J., Arzheimer, K., Campbell, R., \& Cowley, P. (2017). Candidate localness and voter choice in the 2015 general election in England. Elsevier Political Geography, 59, 61-71.

Fitzgerald, J. (2018). Close to Home: Local ties and voting radical right in Europe. Cambridge Studies in Public Opinion and Political Psychology. Cambridge, London: Cambridge University Press.

Fiva, J. H., \& Halse, A. H. (2016). Local favoritism in at-large proportional representation systems. Journal of Public Economics, 143, 15-26.

Fiva, J. H., Halse, A. H., \& Smith, D. M. (2021). Local representation and voter mobilization in closedlist proportional representation systems. Quarterly Journal of Political Science, 16(2), 185-213. https://doi.org/10.1561/100.00019147.

Garand, J. C. (1988). Localism and regionalism in presidential elections: Is there a home state or regional advantage? SAGE Publications West. The Political Quarterly, 41, 85-103.

Gimpel, J. G., Karnes, K. A., McTague, J., \& Pearson-Merkowitz, S. (2008). Distance-decay in the political geography of friends-and-neighbors voting. Political Geography, 27, 231-252.

Górecki, M. A., \& Marsh, M. (2012). Not just 'friends and neighbours': Canvassing, geographic proximity and voter choice. European Journal of Political Research, 51(5), 563-582.

Gschwend, T., \& Zittel, T. (2015). Do constituency candidates matter in German federal elections? The personal vote as an interactive process. Electoral Studies, 39, 338-349.

Inglis, T., \& Donnelly, S. (2011). Local and national belonging in a globalised world. Irish Journal of Sociology, 19, 127-143.

Jacobs, N. F., \& Munis, B. K. (2019). Place-based imagery and voter evaluations: Experimental evidence on the politics of place. Political Research Quarterly, 72, 263-277.

Johnson, C., \& Rosenblatt, G. (2007). Do MPs have the "right stuff"? Oxford University Press Parliamentary Affairs, 60, 164-169.

Key, V. (1949). Southern politics in state and nation. New Yorks: Vintage Books.

Lewis-Beck, M. S., \& Rice, T. W. (1983). Localism in presidential elections: The home state advantage. American Journal of Political Science, 27(3), 548-556.

Meredith, M. (2013). Heterogeneous friends-and-neighbors voting. Working paper. https://www.sas. upenn.edu/ marcmere/workingpapers/HeterogeneousLocalism.pdf

Papke, L. E., \& Wooldridge, J. M. (1996). Econometric methods for fractional response variables with an application to 401 (k) plan participation rates. Journal of Applied Econometrics, 11, 619-632.

Parker, A. J. (1982). The "friends and neighbours" voting effect in the Galway West constituency. Political Geography Quarterly, 1, 243-262.

Put, G.-J., von Schoultz, Å., \& Isotalo, V. (2020). Fighting over friends and neighbors: The effect of intercandidate geographic distance on intra-party competition. Political Geography, 81, 102219. 
Sekhon, J. S. (2008). Multivariate and propensity score matching software with automated balance optimization: The matching package for r. Journal of Statistical Software, 47, 1-52.

Sekhon, J. S., Mebane Jr, W. R. (1998). Genetic optimization using derivatives. Political Analysis, $187-210$.

Shugart, M. S., Valdini, M. E., \& Suominen, K. (2005). Looking for locals: Voter information demands and personal vote-earning attributes of legislators under proportional representation. American Journal of Political Science, 49, 437-449.

Shugart, M. S., \& Wattenberg, M. P. (2001). Mixed-member electoral systems: A definition and typology. Mixed-member electoral systems: The best of both worlds (pp. 9-24). Oxford: Oxford University Press.

Sniderman, P. M., Hagendoorn, L., \& Prior, M. (2004). Predisposing factors and situational triggers: Exclusionary reactions to immigrant minorities. The American Political Science Review, 98(1), 35-49.

Stokes, D. E., \& Miller, W. E. (1962). Party government and the saliency of congress. Public Opinion Quarterly, 26, 531-546.

Tajfel, H., Billig, M. G., Bundy, R. P., \& Flament, C. (1971). Social categorization and intergroup behaviour. European Journal of Social Psychology, 1, 149-178.

Tatalovich, R. (1975). 'Friends and neighbors' voting: Mississippi, 1943-73. Journal of Politics, 37, 807-814.

Tavits, M. (2010). Effect of local ties on electoral success and parliamentary behaviour: The case of Estonia. Party Politics, 16, 215-235.

Van Bavel, J. J., \& Pereira, A. (2018). The partisan brain: An identity-based model of political belief. Trends in Cognitive Sciences, 22, 213-224.

Publisher's Note Springer Nature remains neutral with regard to jurisdictional claims in published maps and institutional affiliations. 